\title{
MODELING THE IMPACT OF INFORMATION SYSTEM ON ORGANIZATIONAL CULTURE AS A REAL SUPPORT FOR INFORMATION SYSTEM SUCCESS MODEL
}

\author{
Ion SMEUREANU \\ Bucharest University of Economic Studies \\ Ion.smeureanu@csie.ase.ro \\ Bassel DIAB \\ Bucharest University of Economic Studies \\ Diab_85@hotmail.com
}

\begin{abstract}
This article presents a model which investigates how organizations in Lebanon perceive the role of information system in enhancing the quality of information shared among its employees. It mainly focuses on the contribution of organizational culture to improving the core features of information that are: accuracy, completeness, currency and format. A sample of 100 organizations has been empirically tested through a survey. Findings showed that the majority of surveyed companies believe that IS promotes the role of internal culture in exchanging information of high quality.
\end{abstract}

Keywords: information quality, information sharing attitudes, information system, information system success model, organizational culture.

JEL classification: C12, M14, M15

DOI: $10.12948 / \mathrm{ie} 2019.05 .03$

\section{Introduction}

DeLone and McLean's Information System Success Model (ISSM), the original and then the updated one (Figure 1), has been used by most of researchers as a theoretical basis or a base model useful to investigate the role of six correlated constructs or dimensions in achieving IS success [1], [2]. On the other side, there is no consensus on the definitions of organizational culture, specifically its elements or components and thereafter the optimal measurement of its role in organizations. However, literature reveals that measuring information sharing attitudes and perceptions of information system strategy is a significant way to recognize the role of organizational culture in the field of information system research [3], [4].

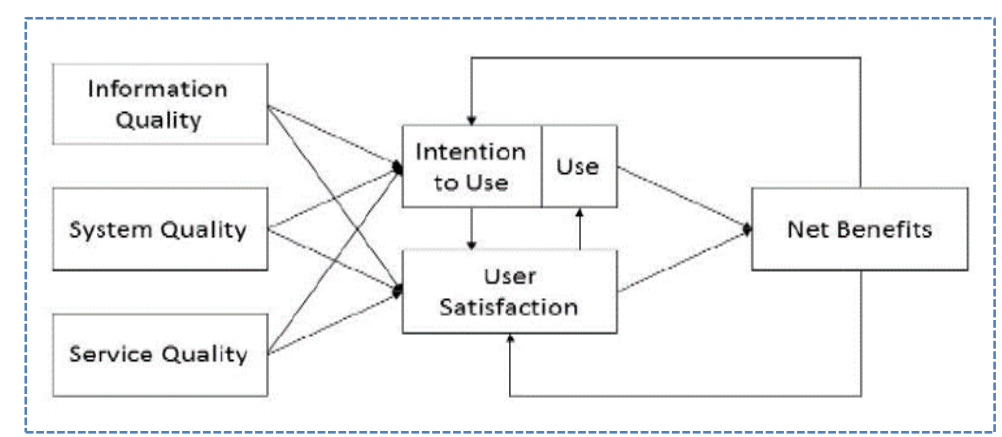

Figure 1. The ISSM (DeLone \& McLean, 2003) updated 
www.conferenceie.ase.ro

\section{Problem statement and evolution}

The problem exists in that the majority of previous studies have explored the effectiveness of ISSM dimensions in maximizing the net benefits of IS and consequently ensuring the IS success (DeLone \& McLean, 2003; Wang et al., 2007; Ramdan, 2014; Weerdt, 2018). Whereas the main objective of this article is to develop a theoretical framework (Figure 2) based on relevant literature, where it goes further by researching the antecedents to those dimensions. To make a long story short, it aims to identify the correlation between organizational culture, mainly Information Sharing Attitudes \& Perceptions of IS Strategy aspects, and Information Quality being a major dimension of the updated ISSM model of DeLone and McLean (2003). Therefore, the authors tried to test the potency of organizational culture in being an antecedent or a real enabler to high information quality, where Intention to use IS is the intermediary between organizational culture and information quality, as the relationship between information quality and intention to use was strongly supported in literature unlike that between information quality and Use [5].

In addition, social influence construct of the Unified Theory of Acceptance and Use of Technology (UTAUT, Venkatesh et al., 2003) [6] was integrated as a direct influencer on behavioral intention to use IS due to strong support presented by the meta-analysis of Dwivedi et al. (2011) [7]. Gender, age, experience and voluntariness of use were adopted as moderating factors between social influence and intention to use IS [6].

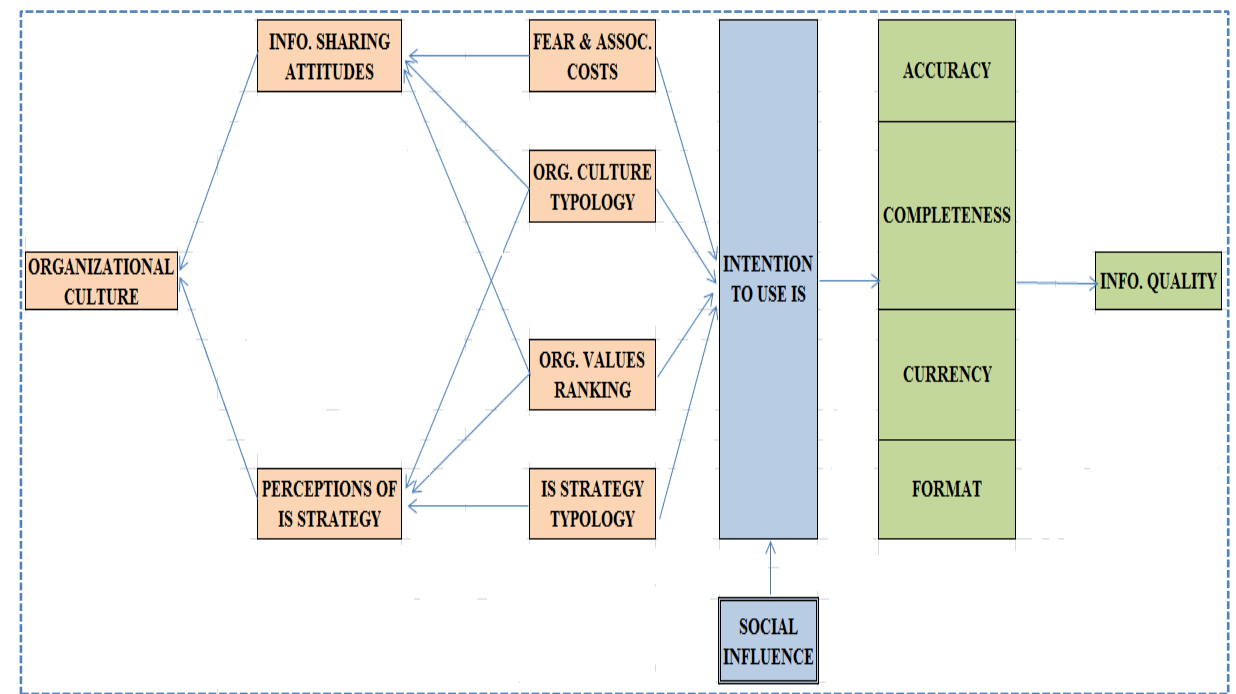

Figure 2. The proposed theoretical concept (self-developed)

\section{Research methodology}

A number of hypotheses are posed based on the suggested theoretical concept which, in turn, has been subject to validation. Hypotheses have been empirically tested through a questionnaire with 100 respondents occupying senior managerial positions in different companies in Lebanon, operating in various industries. The questionnaire was designed based on selfdeveloped set of questions as follows:

1. General questions about: gender, age, experience and whether it is a mandatory or voluntary use of IS.

2. Does the organizational culture support sharing of information?

3. Is info sharing ranked as a priority value above other values?

4. Does the organizational culture support sharing of accurate information?

5. Does the organizational culture support sharing of complete information?

6. Does the organizational culture support sharing of up-to-date information? 
www.conferenceie.ase.ro

7. Does the organizational culture care only about content, or format too?

8. Does IS provide accurate information?

9. Does IS provide complete information?

10. Does IS provide up-to-date information?

11. Does IS provide information in a good and easy to understand format?

12. Is IS strategy perceived as aggressive or conservative?

13. Does managerial culture reward employees for sharing accurate, complete and updated info in an easy form?

\begin{tabular}{||c|c|c|c|c|c||}
\hline $\begin{array}{c}\text { Strongly } \\
\text { disagree }\end{array}$ & Disagree & $\begin{array}{c}\text { Slightly } \\
\text { disagree }\end{array}$ & $\begin{array}{c}\text { Slightly } \\
\text { agree }\end{array}$ & Agree & $\begin{array}{c}\text { Strongly } \\
\text { agree }\end{array}$ \\
\hline 1 & 2 & 3 & 4 & 5 & 6 \\
\hline
\end{tabular}

Hypotheses are as follows:

1. Fear and associated costs have a negative impact on information sharing, consequently on information quality.

2. Typology of organizational culture has a positive impact on information sharing, consequently on information quality.

3. Ranking of organizational values has a positive impact on information sharing, consequently on information quality.

4. Typology of IS strategy has a positive impact on information sharing, consequently on information quality.

5. Accuracy, completeness, currency and format have positive impacts on information sharing, consequently on information quality.

6. Organizational culture, precisely information sharing attitudes and perceptions of IS strategy, has a positive impact on information sharing and consequently on information quality.

7. Social influence has a positive impact on the intention to use IS and consequently on information quality.

8. Intention to use IS is an effective intermediary between organizational culture and information quality.

The hypotheses presented are numerous; however, the authors decided to focus on the last four hypotheses, based on data availability, regarding information sharing and information quality of the information system actually applied as well as the way information system and organizational culture behave in the changing process they both have to face.

\section{Findings and interpretations}

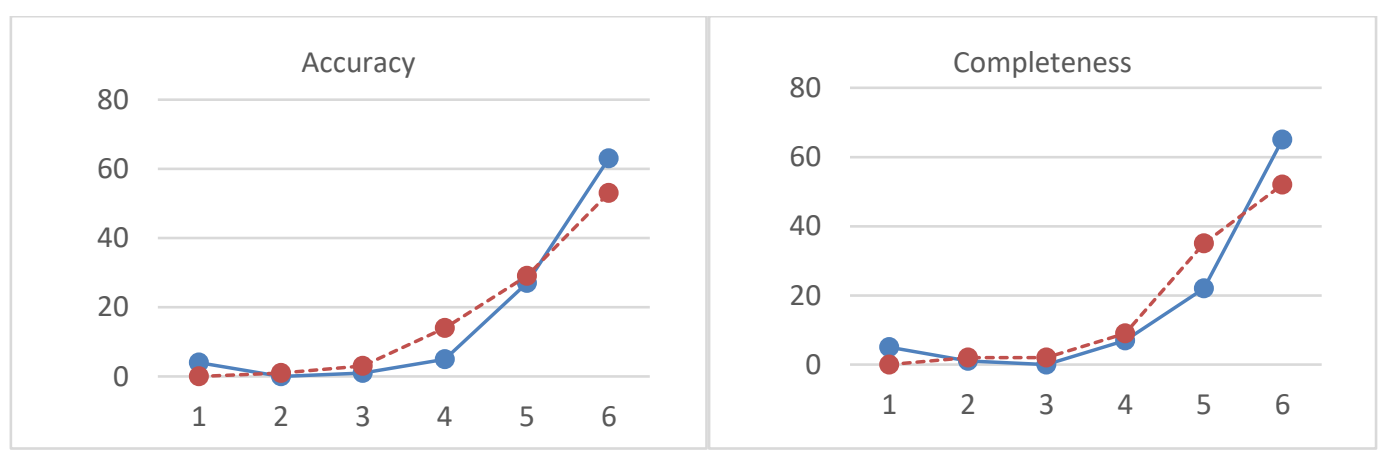


www.conferenceie.ase.ro

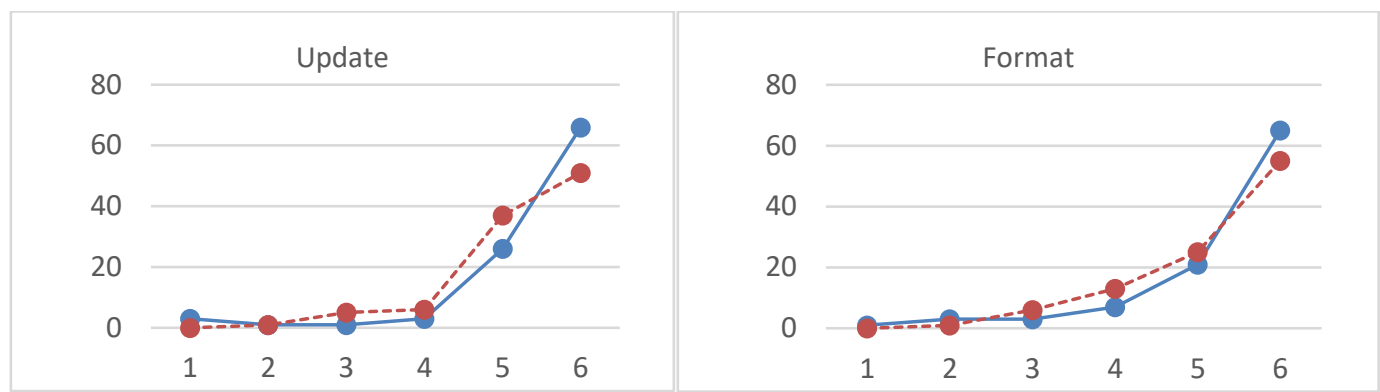

Figure 3. Matching IS features (dotted blue) with organizational culture expectations (dotted Red)

For all four characteristics, the shapes (Figure 3) reveal the same spreading of information system. First group, containing few companies, benefits of IS support to implement their strategies; however they do not recognize the significant role of information sharing within organizational culture. There is another group of companies for which the expectations from IS in terms of spreading internal culture are not achieved. Lastly, most of surveyed companies understand perfectly the importance of new technology or information system, not only in supporting the spreading of internal culture which favors information sharing and cooperation, but also in improving the quality of shared information in terms of completeness, accuracy, upto-date information and presentation in easy to understand format. Sometimes information systems offer more than what organizational culture can capitalize.

Looking into details, Completeness seems to work in tandem with Updating and Accuracy with Format. Features of the first couple are much more similar and closer to each other than those of the second pair; so for the next analysis we can give up to Update.

In 3-D space of Completeness, Format and Accuracy, the points fall into two clearly delimited categories (Figure 4a, 4b). First category includes companies which under-estimate the importance of information system with respect to organizational culture, while the second one involves the majority of companies which perceive that information system provides real leverage to information sharing within organizational culture, highly ranking the value of cooperation.

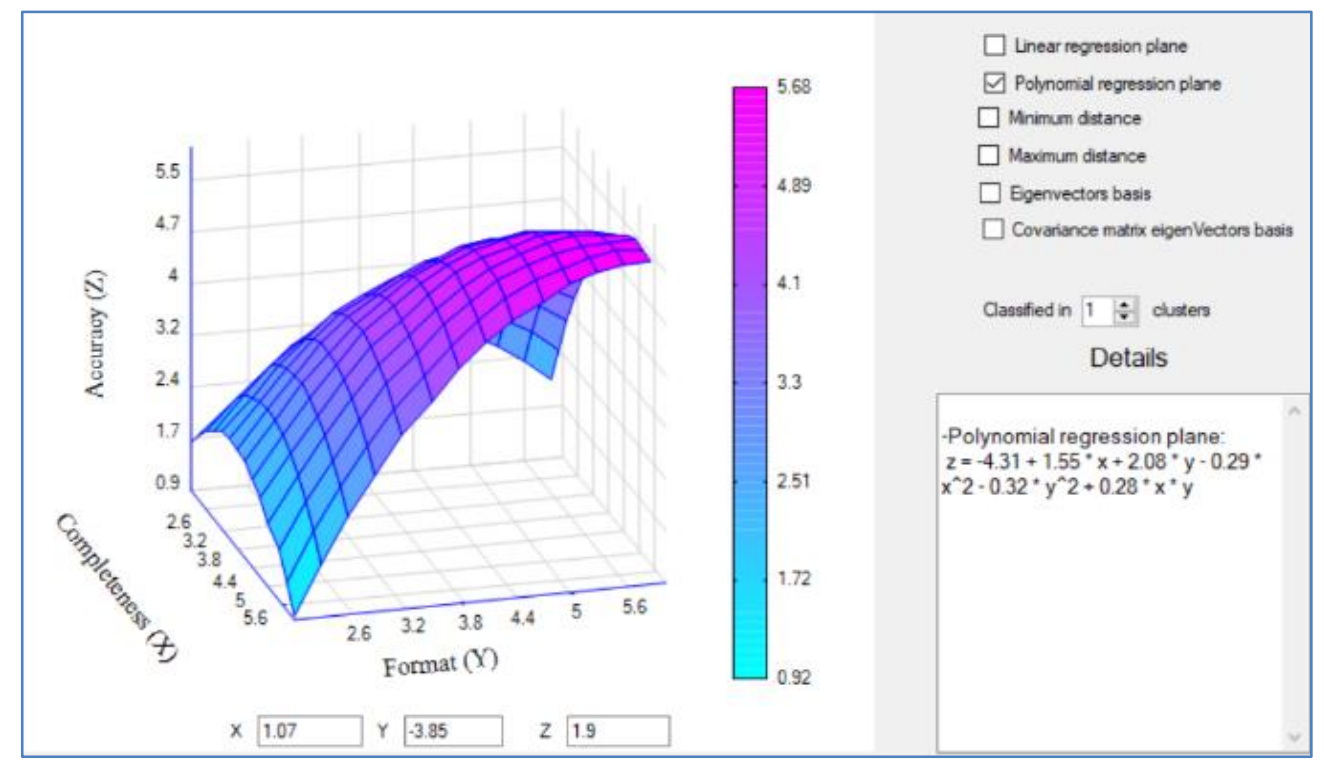

Fig. 4a. Correlation among accuracy, completeness and data format as seen by organizational culture (polynomial regression plane: $z=-4.31+1.55 * x+2.08 * y-0.29 *$ $\left.x^{\wedge} 2-0.32 * y^{\wedge} 2+0.28 * x * y\right)$ 


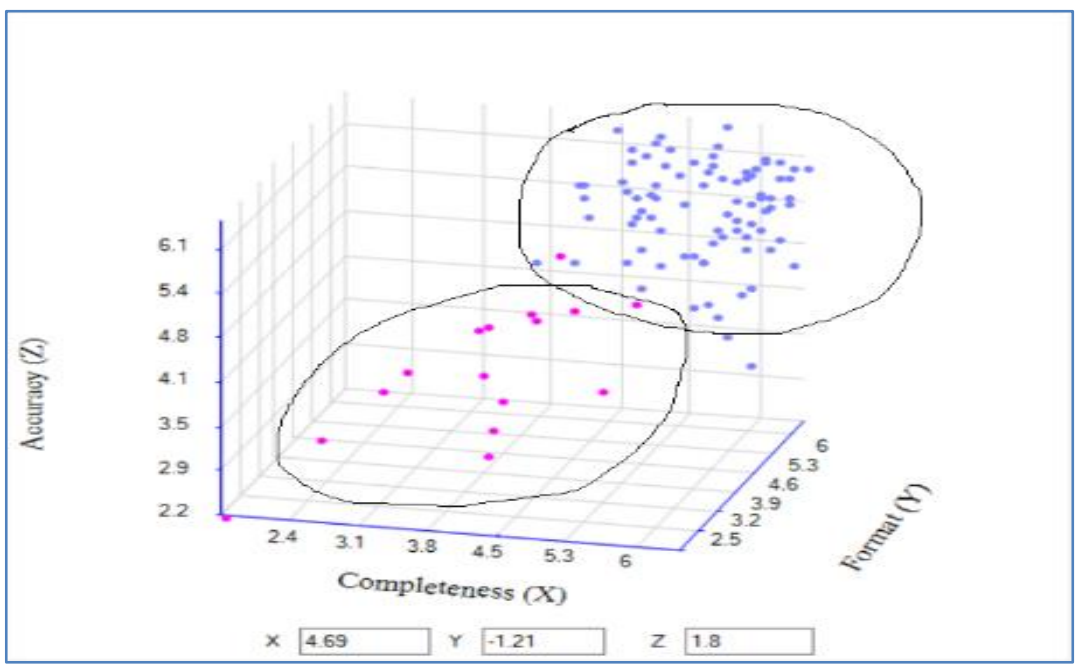

Fig. 4b. Clusters of companies regarding perception of information within organizational culture

Information system - organizational culture dependencies are reciprocal in the sense that an information system, supported by the latest facilities, contributes to the spread of a highly performing and efficient organizational culture. At the same time, a sound organizational culture facilitates the promotion and integration of online corporate communication.

Nevertheless, the authors started from the premise that a stronger causality manifests from information system toward organizational culture which successively provides a validation of how the information system is mapped to the organizational requirements.

To test the goodness of fit between IS progress and OC perceptions under a CHI Square paradigm, the authors took the technological changes (more stable and easier to have more precisely measures) as expected values for OC, in terms of accuracy, completeness, updating and data format.

For actual perceptions of OC over the same characteristics, we conclude that 70.29 >> 30.6 critical value at 0.01 significance for 15 degree of freedom; this shows a major improvement of OC based on IS developments. Consequently, null hypothesis (no influences of IS on OC) is rejected with a rate over $99 \%$.

\section{Conclusions}

The value added that this article provides concerns the investigation and analysis of the impact of organizational culture on a major factor leading towards the success of IS applied in organizations, which is Information quality i.e. OC as antecedent to info quality being a critical success factor of ISSM.

Moreover, the authors navigated the extant literature on internal cooperation, knowledge sharing, and their enablers or inhibitors within organizations and succeeded to develop a detailed theoretical framework. This framework encompasses a set of six correlated agents affecting organizational culture: fear and associated costs, organizational culture typology, organizational values ranking, IS strategy typology, information sharing attitudes and perceptions of IS strategy.

This framework opens the door to the authors to conduct an extended study covering all of these six agents and the remaining hypotheses. It should also draw the attention of other scholars to undertake further research. 
www.conferenceie.ase.ro

Finally, this paper focuses on businesses running in diversified industries in Lebanon, and then an important question might appear: would IS still have the same impact on organizational culture and consequently on information quality if the same survey was conducted in Romania, on organizations operating in a single industry, or on SMEs compared to big companies?

\section{References}

[1] A. I. Ojo, "Validation of the DeLone and McLean Information Systems Success Model," Healthcare Informatics Research, 23 (1), 2017, pp. 60-66.

[2] C. V. Weerdt, "The path to benefits: Investigating the role of organizational culture toward information system benefits", $\mathrm{PhD}$ dissertation, Kent State University, 2018, pp. 19-21.

[3] S. Mardiana et al., "How organizational culture affects information system success: The case of an Indonesia IT-based company," Journal of Information Systems Engineering and Business Intelligence, 4 (2), 2018, pp. 84-95.

[4] S. Heathfield, "Learn the main components of communication in the workplace". [Online]. Available: https:// thebalancecareers.com/communication-in-the-workplace-1918089/. [Updated Sept. 16, 2018].

[5] T. L. M. Suryanto et al., "Analysis of the effect of information system quality to intention to reuse of Employee Management Information System (SIMPEG) based on Information Systems Success Model," in Proc. of MATEC Web of Conferences, 2016, 58:03001 DOI: $10.1051 /$ matecconf/20165803001

[6] V. Venkatesh et al., "User acceptance of information technology: Toward a unified view,"MIS Quarterly, 27 (3), 2003, pp. 425-478.

[7] Y. K. Dwivedi et al., "A meta-analysis of the Unified Theory of Acceptance and Use of Technology (UTAUT),". In Proc. of the International Working Conference, Hamburg, Germany, September 22-24, 2011. pp. 155-170. 